\title{
Maternal and best friends' influences on meal-skipping behaviours
}

\author{
Natalie Pearson ${ }^{1,2 *}$, Lauren Williams ${ }^{2}$, David Crawford ${ }^{2}$ and Kylie Ball ${ }^{2}$ \\ ${ }^{1}$ School of Sport, Exercise and Health Sciences, Loughborough University, Loughborough, Leicestershire LE11 $3 T U$, UK \\ ${ }^{2}$ Centre for Physical Activity and Nutrition Research, School of Exercise and Nutrition Sciences, Deakin University, Burwood, \\ VIC, Australia
}

(Submitted 15 April 2011 - Final revision received 13 October 2011 - Accepted 13 October 2011 - First published online 31 January 2012)

\section{Abstract}

Skipping meals is particularly common during adolescence and can have a detrimental effect on multiple aspects of adolescent health. Understanding the correlates of meal-skipping behaviours is important for the design of nutrition interventions. The present study examined maternal and best friends' influences on adolescent meal-skipping behaviours. Frequency of skipping breakfast, lunch and dinner was assessed using a Web-based survey completed by 3001 adolescent boys and girls from years 7 and 9 of secondary schools in Victoria, Australia. Perceived best friend and maternal meal skipping, modelling of healthy eating (eating healthy food, limiting junk food, eating fruit and vegetables) and weight watching were assessed. Best friend and maternal factors were differentially associated with meal-skipping behaviours. For example, boys and girls who perceived that their best friend often skipped meals were more likely to skip lunch $(\mathrm{OR}=2 \cdot 01,95 \% \mathrm{CI} 1.33,3.04$ and $\mathrm{OR}=1.93,95 \%$ CI 1.41, 2.65; $P<0.001)$. Boys and girls who perceived that their mother often skipped meals were more likely to skip breakfast ( $\mathrm{OR}=1.48,95 \%$ CI $1.01,2.15 ; P<0.05$ and $\mathrm{OR}=1.93,95 \%$ CI $1.42,2.59$; $P<0.001)$ and lunch $(\mathrm{OR}=2.05,95 \% \mathrm{CI} 1.35,3.12$ and $\mathrm{OR}=2.02,95 \%$ CI $1.43,2.86 ; P<0.001)$. Educating adolescents on how to assess and interpret unhealthy eating behaviours that they observe from significant others may be one nutrition promotion strategy to reduce meal-skipping behaviour. The involvement of mothers may be particularly important in such efforts. Encouraging a peer subculture that promotes regular consumption of meals and educates adolescents on the detrimental impact of meal-skipping behaviour on health may also offer a promising nutrition promotion strategy.

\section{Key words: Maternal influences: Best friends: Adolescents: Meal skipping: Breakfast: Lunch: Dinner}

Nutrition plays a critical role in adolescent health and development. Adolescence is a time when the physiological need for a high nutritional quality diet is particularly important, not least because of the rapid growth (stature and weight) spurt experienced during this developmental phase ${ }^{(1,2)}$. However, adolescence is also a period of increased autonomy, and is often characterised by exploratory and sometimes unhealthy and erratic eating behaviours, such as meal skipping and snacking ${ }^{(3,4)}$. Skipping meals is particularly common during middle and late adolescence ${ }^{(4)}$. Breakfast is the meal most often skipped $^{(5,6)}$. A number of studies have shown that girls are more likely to skip meals than are boys ${ }^{(6-9)}$. Skipping meals can have a significant impact upon adolescent health. For example, meal skipping is an unhealthy method of weight control ${ }^{(10)}$, is related to poorer diet quality and suboptimal nutrient intakes ${ }^{(11,12)}$, can interfere with cognition and learning among children ${ }^{(13)}$, is associated with mental distress and impaired academic performance among adolescents $^{(14)}$, and has been implicated in the development of obesity $^{(15,16)}$. Furthermore, evidence suggests that eating habits and behaviours during adolescence track into adulthood ${ }^{(17,18)}$. Given such evidence, decreasing the frequency of meal skipping among adolescents is an important target for nutrition interventions. In order to develop effective interventions aimed at reducing meal skipping, it is important to have a detailed understanding of the determinants of these behaviours.

Adolescents' eating behaviours are known to be strongly influenced by their social environments, which include family, friends and peer networks ${ }^{(4,19)}$. The family is a critical context for the development of eating behaviours, and parents play a key role in the establishment and maintenance of their child's eating behaviours ${ }^{(4,20)}$. Previous research has identified numerous pathways by which parents may shape the eating behaviours of their children. For example, a plethora of research has shown parental modelling of eating behaviours (e.g. consumption of fruit, vegetables and fats) to be a key determinant of adolescent consumption of these same foods ${ }^{(19,21,22)}$. In a recent review, parental breakfast eating and living in two-parent families were found to be the correlates most often associated with adolescents' breakfast

Abbreviation: YEP, Youth Eating Patterns.

*Corresponding author: N. Pearson, fax +44 1509 226301, email n.l.pearson@lboro.ac.uk 
consumption. There is much less evidence, however, of the correlates of other meal-skipping behaviours ${ }^{(23-25)}$.

While research has shown that parental influence on health behaviours is maintained as children age and leave the home $^{(26)}$, the influence of friends and peers becomes increasingly salient ${ }^{(4)}$. Adolescents spend a substantial amount of time with friends, and some research has shown that adolescents report that the attitudes, encouragement and behaviours of friends and peers influence their food choice and eating behaviours ${ }^{(27-30)}$. Examining social influences on meal-skipping behaviours is difficult because adolescents may not be aware of these social influences. Furthermore, social influences on meal-skipping behaviours may be indirect, rather than direct ${ }^{(4,31)}$. For example, it could be hypothesised that adolescents who perceive that their mother or best friend eats a healthy diet are less likely to skip meals, because skipping meals is an unhealthy eating behaviour. Few studies, however, have examined such associations, and few studies have concurrently examined the relative associations of parental and best friends' characteristics with adolescent eating behaviours ${ }^{(32,33)}$, or examined meal-skipping behaviours other than breakfast. Therefore, the present study aimed to examine maternal and best friend correlates of skipping breakfast, lunch and dinner among adolescent boys and girls.

\section{Methods}

\section{Study procedure}

Data were drawn from the Youth Eating Patterns (YEP) study. In 2004 and 2005, all co-educational state (government) and Catholic secondary schools (years 7-12) with enrolments over 200, located in the southern metropolitan region of Melbourne and the non-metropolitan region of Gippsland, to the east of Melbourne, were invited to participate in the study. Of the seventy schools (forty-seven metropolitan and twentythree non-metropolitan) that met these criteria, thirty-seven schools (twenty metropolitan and seventeen non-metropolitan) agreed to participate. The YEP survey is an online food habits survey and was administered by teachers during a class when students had access to computers. Study procedures were approved by the Ethics Committee of Deakin University and the Victorian Department of Education and Training and the Catholic Education Office. A detailed description of the YEP survey, participant recruitment and study procedures have been described in previous publications ${ }^{(25,34)}$.

\section{Participants}

All students ( $n$ 9842) from year 7 (aged $12-13$ years) and year 9 (aged 14-15 years) from participating secondary schools were invited to complete the online survey. Teachers distributed parental consent forms via students, asking permission for their child to participate in the study. The consent form also asked parents to provide information about their family circumstances (e.g. marital status, education level, employment status, number of children). Parental consent was obtained for $4502(46 \%)$ of all eligible students. Online surveys were completed by 3264 adolescents (33\%). Due to incomplete data on one or more of the variables of interest, 263 adolescents were excluded from analyses for the present study.

\section{Measures}

The YEP survey collected information on demographic characteristics of adolescents including date of birth, school year and sex.

\section{Skipping meals}

Meal skipping was assessed by asking adolescents how often over the past month they had: 'skipped breakfast', 'skipped lunch' and 'skipped dinner'. Possible responses were 'not in the last month', 'once/twice a month', 'once/twice a week', 'most days' or 'every day'. Frequencies for all responses are displayed in Table 1. Adolescents were categorised as 'skippers' if they reported skipping meals on 'most days' or 'every day'. Categories for 'skippers' have previously been used from this dataset; for consistency, the same cut points were used in the present study ${ }^{(8,25)}$.

\section{Best friend and maternal factors}

Adolescents were asked to provide a rating of their agreement with two questions about their best friends and the same two questions about their mother: 'my best friend/mother often skips meals' and 'my best friend/mother watches their weight'. Response options were given on a three-point Likert scale: (1) disagree, (2) not sure, (3) agree (see Table 1 for frequencies for all responses). Best friend/maternal skipping meals and best friend/mother watching their weight were collapsed into two groups: disagree/not sure $v$. agree.

Perceived modelling of healthy eating of best friends and mothers was assessed with items developed specifically for the present study. For each, the adolescent provided a rating of their agreement with four separate statements: 'my best friend/mother eats healthy food', 'limits junk foods', 'eats vegetables most days' and 'eats fruit most days' (1) disagree, (2) not sure or (3) agree (see Table 1 for frequencies for all responses). Each item was recoded as (1) agree and (0) disagree/not sure. Then, two variables were created by summing the four items (Cronbach's $\alpha=0.77$ for perceived modelling of healthy eating by best friend and Cronbach's $\alpha=0.71$ for perceived modelling of healthy eating by mother), and then dichotomising by the median into high and low modelling.

\section{Statistical analysis}

All analyses were conducted using Stata 11 (Stata Corporation, College Station, TX, USA, 2003). Descriptive statistics including frequencies, means and standard deviations were calculated for all study variables according to sex and year level of adolescent participants.

Bivariate logistic regression analyses (model 1) were conducted to examine associations between the best friend and maternal variables and adolescent meal skipping. All predictor 
Table 1. Description of all variables before dichotomisation for analyses*

\begin{tabular}{|c|c|c|c|c|}
\hline & \multicolumn{2}{|c|}{ Sex } & \multicolumn{2}{|c|}{ School year } \\
\hline & Boys ( $n$ 1390) & Girls ( $n$ 1611) & Year 7 ( $n$ 1835) & Year $9(n 1166)$ \\
\hline \multicolumn{5}{|l|}{ Skips breakfast (\%) } \\
\hline Not in the last month & $61 \cdot 1$ & 45.4 & $54 \cdot 6$ & $49 \cdot 6$ \\
\hline Once/twice a month & $14 \cdot 2$ & $16 \cdot 8$ & 14.6 & $17 \cdot 2$ \\
\hline Once/twice a week & 9.5 & 14.4 & $12 \cdot 1$ & $12 \cdot 2$ \\
\hline Most days & $11 \cdot 3$ & $18 \cdot 1$ & 14.6 & $15 \cdot 4$ \\
\hline Every day & 3.9 & $5 \cdot 3$ & 4.1 & $5 \cdot 6$ \\
\hline \multicolumn{5}{|l|}{ Skips lunch (\%) } \\
\hline Not in the last month & 58.9 & $49 \cdot 2$ & $55 \cdot 0$ & $51 \cdot 8$ \\
\hline Once/twice a month & $20 \cdot 6$ & $21 \cdot \overline{7}$ & $20 \cdot 4$ & $22 \cdot 6$ \\
\hline Once/twice a week & $10 \cdot 6$ & $15 \cdot 6$ & 13.3 & $13 \cdot 3$ \\
\hline Most days & 7.6 & 10.9 & $9 \cdot 1$ & $9 \cdot 6$ \\
\hline Every day & $2 \cdot 3$ & 2.6 & $2 \cdot 2$ & $2 \cdot 7$ \\
\hline \multicolumn{5}{|l|}{ Skips dinner (\%) } \\
\hline Not in the last month & 87.6 & 80.5 & 86.6 & $79 \cdot 3$ \\
\hline Once/twice a month & 7.9 & $12 \cdot 2$ & 8.3 & $13 \cdot 3$ \\
\hline Once/twice a week & $2 \cdot 3$ & $5 \cdot 2$ & $2 \cdot 8$ & $5 \cdot 3$ \\
\hline Most days & 1.2 & 1.3 & 1.5 & 0.9 \\
\hline Every day & 1.0 & 0.8 & 0.8 & 1.2 \\
\hline \multicolumn{5}{|c|}{ Best friend often skips meals (\%) } \\
\hline Disagree & 39.2 & 46.5 & 43.9 & 41.8 \\
\hline Not sure & $45 \cdot 0$ & 30.9 & 37.6 & 37.2 \\
\hline Agree & $15 \cdot 8$ & $22 \cdot 6$ & 18.5 & $21 \cdot 0$ \\
\hline \multicolumn{5}{|c|}{ Best friend eats healthy food (\%) } \\
\hline Disagree & $12 \cdot 2$ & $12 \cdot 9$ & 9.9 & $16 \cdot 8$ \\
\hline Not sure & $47 \cdot 3$ & $32 \cdot 2$ & 38.9 & 39.5 \\
\hline Agree & 40.5 & 54.9 & $51 \cdot 2$ & 43.7 \\
\hline \multicolumn{5}{|c|}{ Best friend limits junk foods (\%) } \\
\hline Disagree & $22 \cdot 8$ & 23.1 & 21.6 & 27.4 \\
\hline Not sure & 51.7 & $42 \cdot 3$ & $48 \cdot 3$ & $44 \cdot 1$ \\
\hline Agree & $25 \cdot 5$ & 34.6 & 30.1 & 28.5 \\
\hline \multicolumn{5}{|c|}{ Best friend eats vegetables most days (\%) } \\
\hline Disagree & 13.4 & 11.9 & $12 \cdot 2$ & $13 \cdot 2$ \\
\hline Not sure & $49 \cdot 4$ & 35.5 & 42.6 & 40.9 \\
\hline Agree & $37 \cdot 2$ & $52 \cdot 6$ & $45 \cdot 2$ & $45 \cdot 9$ \\
\hline \multicolumn{5}{|c|}{ Best friend eats fruit most days (\%) } \\
\hline Disagree & 13.7 & 14.5 & $13 \cdot 1$ & $15 \cdot 7$ \\
\hline Not sure & $49 \cdot 2$ & $25 \cdot 4$ & $32 \cdot 7$ & 34.6 \\
\hline Agree & $37 \cdot 1$ & $60 \cdot 1$ & $54 \cdot 2$ & 49.7 \\
\hline \multicolumn{5}{|c|}{ Best friend watches their weight (\%) } \\
\hline Disagree & 23.3 & 23.4 & $20 \cdot 7$ & $27 \cdot 6$ \\
\hline Not sure & 48.7 & 35.9 & 43.4 & 39.4 \\
\hline Agree & $28 \cdot 0$ & $40 \cdot 7$ & 35.9 & 33.0 \\
\hline \multicolumn{5}{|c|}{ Mother often skips meals (\%) } \\
\hline Disagree & $57 \cdot 1$ & 60.4 & 55.5 & 57.9 \\
\hline Not sure & $27 \cdot 7$ & $24 \cdot 2$ & $25 \cdot 9$ & $25 \cdot 8$ \\
\hline Agree & $15 \cdot 2$ & $15 \cdot 4$ & 18.6 & $16 \cdot 3$ \\
\hline \multicolumn{5}{|c|}{ Mother eats healthy food (\%) } \\
\hline Disagree & 2.9 & 2.9 & $2 \cdot 2$ & 3.9 \\
\hline Not sure & $15 \cdot 3$ & $14 \cdot 3$ & $14 \cdot 3$ & $15 \cdot 5$ \\
\hline Agree & $81 \cdot 8$ & $82 \cdot 8$ & 83.5 & $80 \cdot 6$ \\
\hline Mother limits junk foods & & & & \\
\hline Disagree & $5 \cdot 1$ & $5 \cdot 8$ & 4.5 & 6.9 \\
\hline Not sure & 18.9 & $17 \cdot 7$ & $18 \cdot 1$ & 18.5 \\
\hline Agree & $76 \cdot 0$ & $76 \cdot 5$ & 77.4 & 74.6 \\
\hline Mother eats vegetables & & & & \\
\hline Disagree & $2 \cdot 4$ & $2 \cdot 1$ & 1.9 & $2 \cdot 7$ \\
\hline Not sure & $12 \cdot 5$ & $7 \cdot 1$ & 9.2 & $10 \cdot 2$ \\
\hline Agree & $85 \cdot 1$ & 90.8 & 88.9 & $87 \cdot 1$ \\
\hline Mother eats fruit most $d$ & & & & \\
\hline Disagree & 4.7 & 5.6 & 4.4 & $6 \cdot 3$ \\
\hline Not sure & $22 \cdot 1$ & $19 \cdot 2$ & $20 \cdot 8$ & $19 \cdot 9$ \\
\hline Agree & 73.2 & $75 \cdot 2$ & 74.8 & 73.8 \\
\hline Mother watches her wei & & & & \\
\hline Disagree & 4.9 & 9.4 & $6 \cdot 3$ & $9 \cdot 1$ \\
\hline Not sure & 30.6 & $29 \cdot 3$ & $29 \cdot 2$ & $31 \cdot 1$ \\
\hline Agree & 64.5 & $61 \cdot 3$ & 64.5 & $59 \cdot 8$ \\
\hline
\end{tabular}

* Skipping meals: adolescents were categorised as 'skippers' (of breakfast, lunch, dinner) if they reported skipping meals on 'most days' or 'every day' for analyses. Variables best friend/mother often skips meals and best friend/mother watches their weight were collapsed into two groups: disagree/not sure $v$. agree for analyses. Best friend and maternal modelling of healthy eating variables were created from the variables 'my best friend/mother eats healthy food', 'limits junk foods', 'eats vegetables most days' and 'eats fruit most days'. Each item was recoded as (1) 'agree' and (0) disagree/not sure. Two variables were then created by summing the four items (Cronbach's $\alpha=0.77$ for perceived modelling of healthy eating by best friend and Cronbach's $\alpha=0.71$ for perceived modelling of healthy eating by mother), and then dichotomising by the median into high and low modelling. 
Table 2. Description of frequency of skipping meals and friend and maternal predictor variables by adolescent sex and year level†

\begin{tabular}{|c|c|c|c|c|}
\hline & \multicolumn{2}{|c|}{ Sex } & \multicolumn{2}{|c|}{ School year } \\
\hline & Boys ( $n$ 1390) & Girls ( $n$ 1611) & Year 7 (n 1835) & Year $9(n 1166)$ \\
\hline \multicolumn{5}{|l|}{ Outcome variables (\% skips) } \\
\hline Skipping breakfast & $15 \cdot 1^{\star \star \star}$ & $23 \cdot 4^{\star \star \star}$ & $18 \cdot 7$ & $19 \cdot 0$ \\
\hline Skipping lunch & $9 \cdot 9^{\star * \star}$ & $13 \cdot 3^{\star \star \star}$ & 11.4 & $12 \cdot 2$ \\
\hline Skipping dinner & $2 \cdot 2$ & $2 \cdot 0$ & $2 \cdot 1$ & $2 \cdot 1$ \\
\hline \multicolumn{5}{|l|}{ Predictor variables } \\
\hline Best friend often skips meals (\% agrees) & $15 \cdot 8^{\star \star *}$ & $22 \cdot 6^{\star \star \star}$ & $18 \cdot 5^{*}$ & $21 \cdot 0^{*}$ \\
\hline Best friend models healthy eating (\% high modelling) & $28.5^{\star \star *}$ & $42 \cdot 1^{\star \star \star}$ & $37 \cdot 2^{*}$ & $33.3^{*}$ \\
\hline Best friend watches their weight (\% agrees) & $28 \cdot 0^{* \star *}$ & $40 \cdot 7^{\star \star \star}$ & $36 \cdot 0$ & 33.0 \\
\hline Mother often skips meals (\% agrees) & $15 \cdot 2$ & $15 \cdot 4$ & $18 \cdot 6$ & $16 \cdot 3$ \\
\hline Mother models healthy eating (\% high modelling) & $78.0^{*}$ & $80 \cdot 8^{*}$ & $80.9^{*}$ & $77 \cdot 4^{*}$ \\
\hline Mother watches her weight ( $\%$ agrees) & 64.5 & $61 \cdot 3$ & $64 \cdot 5^{\star *}$ & $59 \cdot 8^{\star *}$ \\
\hline
\end{tabular}

${ }^{\star} P<0.05 ;{ }^{\star \star} P<0.01 ;{ }^{* \star \star} P<0.001$.

$\dagger \chi^{2}$ test for examining differences in categorical variables by adolescent sex and year level.

variables that were significantly associated with meal skipping in the bivariate analyses were entered into multivariate logistic regression models (model 2). All regression models were stratified by sex and adjusted for age (year level) of adolescents, and accounted for potential clustering by school (unit of recruitment) using the 'cluster' command.

\section{Results}

Slightly more of the adolescent sample were girls (53\%) and in year 7 of secondary school (61\%). The mean age of adolescents was $13 \cdot 2$ (sD 1.6) years. Descriptives for each of the variables used in the present study before dichotomisation are presented in Table 1. Best friend and maternal predictor variables and patterns of meal skipping (outcome variables) are described in Table 2 according to adolescent sex and year level.

Tables 3-5 show the results of the bivariate and multivariate logistic regression analyses predicting adolescent breakfast, lunch and dinner skipping, respectively, stratified by sex. After adjusting for all significant variables from model 1, two variables remained significant among boys (model 2, Table 3) and four variables remained significant among girls (model 2, Table 3) with regard to breakfast skipping. Boys and girls who reported high maternal modelling of healthy eating were less likely to skip breakfast, and those who agreed that their mother often skipped meals were more likely to skip breakfast (model 2, Table 3). Girls who agreed that their best friends often skipped meals were more likely to skip breakfast and girls who reported high best friend modelling of healthy eating had lower odds of skipping breakfast (model 2, Table 3).

After adjusting for all significant variables from model 1, two variables remained significant among boys and girls (model 2, Table 4) with regard to skipping lunch. Boys and girls who agreed that their best friend and mother often skipped meals were more likely to skip lunch (model 2, Table 4).

In the fully adjusted model (model 2), boys and girls who reported high levels of maternal modelling of healthy eating were less likely to skip dinner. Girls who agreed that their best friend often skipped meals were more likely to skip dinner (model 2, Table 5).

\section{Discussion}

The aim of the present study was to examine maternal and best friend correlates of meal-skipping behaviour among a sample of Australian adolescents. Results indicated that for

Table 3. Best friend and maternal predictors of skipping breakfast

(Odd ratios and $95 \%$ confidence intervals)

\begin{tabular}{|c|c|c|c|c|c|c|c|c|}
\hline & \multicolumn{8}{|c|}{ Skipping breakfast } \\
\hline & \multicolumn{4}{|c|}{ Boys $(n 1390)$} & \multicolumn{4}{|c|}{ Girls ( $n$ 1611) } \\
\hline & \multicolumn{2}{|c|}{ Model $1 \dagger$} & \multicolumn{2}{|c|}{ Model $2 \ddagger$} & \multicolumn{2}{|c|}{ Model 1† } & \multicolumn{2}{|c|}{ Model $2 \ddagger$} \\
\hline & OR & $95 \% \mathrm{Cl}$ & OR & $95 \% \mathrm{Cl}$ & OR & $95 \% \mathrm{Cl}$ & OR & $95 \% \mathrm{Cl}$ \\
\hline Best friend skips meals & $1 \cdot 27$ & $0.86,1.80$ & & & $1 \cdot 62^{\star \star \star}$ & $1 \cdot 25,2 \cdot 11$ & $1.43^{\star \star}$ & $1.09,1.87$ \\
\hline Best friend models healthy eating & 0.81 & $0.54,1.22$ & & & $0.59^{\star \star \star}$ & $0.47,0.75$ & $0.64^{\star \star \star}$ & $0.49,0.82$ \\
\hline Best friend watches their weight & 0.98 & $0.70,1.36$ & & & 1.03 & $0.82,1.31$ & & \\
\hline Mother often skips meals & $1 \cdot 57^{\star *}$ & $1 \cdot 08,2 \cdot 28$ & $1.48^{*}$ & $1 \cdot 01,2 \cdot 15$ & $2 \cdot 15^{\star \star \star}$ & $1 \cdot 61,2 \cdot 88$ & $1.93^{* \star *}$ & $1.42,2.59$ \\
\hline Mother models healthy eating & $0.53^{\star * *}$ & $0.40,0.73$ & $0 \cdot 55^{\star \star \star}$ & $0.40,0.76$ & $0.57^{\star \star \star}$ & $0.43,0.72$ & $0.68^{\star \star}$ & $0.51,0.91$ \\
\hline Mother watches her weight & 0.89 & $0.66,1.21$ & & & 0.91 & $0.72,1.15$ & & \\
\hline
\end{tabular}

${ }^{\star} P<0.05 ;{ }^{\star \star} P<0.01 ;{ }^{\star \star \star} P<0.001$.

† Model 1: bivariate logistic regression analyses of the association between single predictor and outcome variables (e.g. between mother often skips meals and adolescent breakfast skipping) controlling for school year, and accounting for potential clustering by school.

$\ddagger$ Model 2: multivariate logistic regression analyses. Model 2 includes all predictor variables significantly associated with outcome variables in model 1 as well as controlling for school year, and accounting for potential clustering by school. 
Table 4. Best friend and maternal predictors of skipping lunch

(Odd ratios and $95 \%$ confidence intervals)

\begin{tabular}{|c|c|c|c|c|c|c|c|c|}
\hline & \multicolumn{8}{|c|}{ Skipping lunch } \\
\hline & \multicolumn{4}{|c|}{ Boys ( $n$ 1390) } & \multicolumn{4}{|c|}{ Girls ( $n$ 1611) } \\
\hline & \multicolumn{2}{|c|}{ Model $1 \dagger$} & \multicolumn{2}{|c|}{ Model $2 \ddagger$} & \multicolumn{2}{|c|}{ Model $1 \dagger$} & \multicolumn{2}{|c|}{ Model $2 \ddagger$} \\
\hline & OR & $95 \% \mathrm{Cl}$ & OR & $95 \% \mathrm{Cl}$ & OR & $95 \% \mathrm{Cl}$ & OR & $95 \% \mathrm{Cl}$ \\
\hline Best friend skips meals & $2 \cdot 10^{\star \star \star}$ & $1 \cdot 39,3 \cdot 18$ & $2 \cdot 01^{\star \star \star}$ & $1.33,3.04$ & $2 \cdot 15^{\star \star \star}$ & $1.58,2.92$ & $1.93^{\star \star *}$ & $1.41,2.65$ \\
\hline Best friend models healthy eating & 0.88 & $0.64,1.19$ & & & $0.69^{*}$ & $0.52,0.93$ & 0.77 & $0.57,1.05$ \\
\hline Best friend watches their weight & 1.04 & $0.70,1.54$ & & & 1.06 & $0.79,1.42$ & & \\
\hline Mother often skips meals & $2 \cdot 15^{\star \star \star}$ & $1.42,3.26$ & $2 \cdot 05^{\star \star \star}$ & $1 \cdot 35,3 \cdot 12$ & $2 \cdot 19^{\star \star \star}$ & $1.56,3.09$ & $2 \cdot 02^{\star \star \star}$ & $1.43,2.86$ \\
\hline Mother models healthy eating & 0.62 & $0.38,1.03$ & & & 0.71 & $0.49,1.03$ & & \\
\hline Mother watches her weight & 0.98 & $0.67,1.41$ & & & 1.01 & $0.76,1.36$ & & \\
\hline
\end{tabular}

${ }^{*} P<0.05 ;{ }^{* *} P<0.01 ;{ }^{* * *} P<0.001$.

† Model 1: bivariate logistic regression analyses of the association between single predictor and outcome variables (e.g. between mother often skips meals and adolescent breakfast skipping) controlling for school year, and accounting for potential clustering by school.

¥ Model 2: multivariate logistic regression analyses. Model 2 includes all predictor variables significantly associated with outcome variables in model 1 as well as controlling for school year, and accounting for potential clustering by school.

boys and girls, perceived maternal meal-skipping behaviour was a consistent positive correlate of skipping breakfast and lunch. The present results further indicated that perceived maternal modelling of healthy eating may protect boys and girls from skipping breakfast and dinner. The present results are consistent with previous research that has shown that maternal modelling of eating behaviours is associated with adolescent eating patterns ${ }^{(19,21,22)}$, particularly restrictive eating behaviours such as fasting and skipping meals ${ }^{(35)}$.

The present findings demonstrate that maternal correlates of meal-skipping behaviours are transferable to meals that are likely to be consumed without maternal presence (e.g. lunch). For instance, perceived maternal meal skipping may provide a lingering barrier to healthy eating for adolescents at lunchtime. This is consistent with Bandura's social learning theory which highlights that 'whilst most human behaviour is learnt through observational modelling, on later occasions this coded information serves as a guide for action'(36). Perceived maternal modelling of healthy eating behaviour, however, may only play a role in promoting healthy eating among adolescents when the mother is likely to be present for the meal being consumed, since the present findings showed this correlate was primarily negatively associated with meal skipping at breakfast and dinner. It is also plausible that mothers who model healthy eating (e.g. by consuming fruit and vegetables most days) maintain healthy eating habits (e.g. eating dinner at the table) and a healthy lifestyle generally, and as such, make healthy food available and discourage meal-skipping behaviour. It is also possible that the present findings of an association between mother and adolescent meal-skipping behaviours may be reflective of certain lifestyle patterns whereby mothers who regularly skip meals may have chaotic family schedules where time and availability prevent meals from always being top priority for the family. Even though adolescents become more autonomous with age, the findings of the present study suggest that the influence of mother's eating behaviours on adolescent eating behaviours is important, for both boys and girls, even in environments where the mother may not be present. Given that mothers are key role models for eating and are the primary gatekeepers for food in the home ${ }^{(37,38)}$, nutrition interventions focusing on adolescents may be more effective if they also target mothers.

Table 5. Best friend and maternal predictors of skipping dinner

(Odd ratios and 95\% confidence intervals)

\begin{tabular}{|c|c|c|c|c|c|c|c|c|}
\hline & \multicolumn{8}{|c|}{ Skipping dinner } \\
\hline & \multicolumn{4}{|c|}{ Boys ( $n$ 1390) } & \multicolumn{4}{|c|}{ Girls ( $n$ 1611) } \\
\hline & \multicolumn{2}{|c|}{ Model $1 \dagger$} & \multicolumn{2}{|c|}{ Model $2 \ddagger$} & \multicolumn{2}{|c|}{ Model $1 \dagger$} & \multicolumn{2}{|c|}{ Model $2 \ddagger$} \\
\hline & OR & $95 \% \mathrm{Cl}$ & OR & $95 \% \mathrm{Cl}$ & OR & $95 \% \mathrm{Cl}$ & OR & $95 \% \mathrm{Cl}$ \\
\hline Best friend skips meals & 1.97 & $0 \cdot 88,4.50$ & & & $2 \cdot 29^{*}$ & $1 \cdot 13,4 \cdot 66$ & $2 \cdot 23^{*}$ & $1.09,4.55$ \\
\hline Best friend models healthy eating & $1 \cdot 22$ & $0.63,2 \cdot 37$ & & & 0.57 & $0.25,1.30$ & & \\
\hline Best friend watches their weight & $1 \cdot 11$ & $0.50,2.44$ & & & $1 \cdot 21$ & $0.60,2.42$ & & \\
\hline Mother often skips meals & 2.09 & $0.92,4.78$ & & & 1.80 & $0.80,4.05$ & & \\
\hline Mother models healthy eating & $0 \cdot 31^{\star \star *}$ & $0.16,0.62$ & $0 \cdot 31^{\star \star \star}$ & $0.16,0.62$ & $0.46^{*}$ & $0.24,0.88$ & $0.48^{\star}$ & $0.23,0.96$ \\
\hline Mother watches her weight & 0.48 & $0.23,1.08$ & & & 0.74 & $0.37,1.49$ & & \\
\hline
\end{tabular}

${ }^{\star} P<0.05 ;{ }^{* \star} P<0.01 ;{ }^{* \star *} P<0.001$

† Model 1: bivariate logistic regression analyses of the association between single predictor and outcome variables (e.g. between mother often skips meals and adolescent breakfast skipping) controlling for school year, and accounting for potential clustering by school.

$\ddagger$ Model 2: multivariate logistic regression analyses. Model 2 includes all predictor variables significantly associated with outcome variables in model 1 as well as controlling for school year, and accounting for potential clustering by school. 
Given that Australian adolescents regularly consume their lunch at school, it is unsurprising that those who perceived their best friends to skip meals were more likely to skip lunch. The present findings also show that adolescent girls who perceived their best friend to skip meals were also more likely to skip breakfast and dinner. The influence of peers on eating behaviours is well established in the literature. Previous research has indicated that the eating attitudes and behaviours maintained by friends and peers can influence adolescents' eating behaviours ${ }^{(39)}$. Skipping meals is often a strategy employed for weight reduction, and it is possible that meal-skipping behaviour at lunch is symptomatic of a friendship/peer environment and subculture that emphasises the importance of weight control, joint-dieting and thinness. This is particularly true for girls, who are more likely to value and pursue a thin body as ideal, engage in disordered eating and interact within friendship groups that share similar eating and dieting behaviours ${ }^{(40,41)}$. There is increasing evidence, however, that adolescent boys are also concerned about their bodies and engage in disordered eating strategies, such as skipping meals ${ }^{(42,43)}$. The present results provided no evidence, however, that adolescents who perceived their best friend as 'watching their weight' were more likely to skip meals. It is possible that adolescents are able to identify specific and observable behaviour change strategies (i.e. skipping meals) more readily than a more general weight-related pursuit (i.e. 'watching their weight'), the latter possibly representing a more private position that is not as easily recognised between friends.

Perceived modelling of healthy eating by best friend was not associated with meal-skipping behaviours among boys. This finding is consistent with that of previous research ${ }^{(33,44)}$. The findings of the present study, however, showed that perceived modelling of healthy eating by best friend may protect girls from skipping breakfast. It is interesting that perceived modelling of healthy eating by best friends influenced girls' breakfast skipping behaviours, where best friends' presence is unlikely. As friendship groups often share similar eating attitudes and behaviours, and adolescents tend to gravitate towards those who share similar values and health behaviours to themselves, it is possible that girls who perceive their friends to have healthy eating habits maintain healthy eating habits themselves. Future research is warranted to further understand the sex differences in the role of best friend modelling of eating behaviours on adolescent meal skipping.

In considering these findings, it is important to acknowledge the limitations of the study. The reach of the whole study was low (46\%); however, this is comparative to other large-scale longitudinal studies. The generalisability of the results is limited because our sample was drawn from schools in Victoria, Australia and so does not represent the population at large. The large number of adolescent boys and girls selecting 'not sure' response to many of the study questions may have had an impact on the results. All data were collected by self-report and are subject to socially desirable response bias or other misreporting. The cross-sectional study design does not permit causal inferences to be drawn. The strengths of the study include the large regionally diverse sample of adolescents, consideration of both peer and family correlates of multiple meal behaviours.

Acknowledging its limitations, the findings of the present study are important, since little is known about the social influences on meal-skipping patterns of adolescents. Overall, the present results highlight that perceived maternal and best friend eating behaviours are important correlates of skipping meals among adolescent girls and boys. Educating adolescents on how to assess and interpret unhealthy eating behaviours that they observe from significant others may be one nutrition promotion strategy to reduce meal-skipping behaviour. The involvement of mothers is likely to be particularly important in such efforts. Encouraging a peer subculture that promotes regular consumption of meals and educates adolescents on the detrimental impact of meal-skipping behaviour on health may also offer a promising nutrition promotion strategy.

\section{Acknowledgements}

This study was funded by the Australian Research Council (DP0452044) and the William Buckland Foundation; the National Medical Research Council Senior Research Fellowship (479513 to K. B.); the VicHealth Senior Public Health Research Fellowship to D. C. N. P. carried out the statistical analyses and drafted the paper. L. W. contributed to the drafting of the paper. K. B. was involved in the design and conduct of the study and contributed to the drafting of the paper. D. C. was involved in the design and conduct of the study and contributed to the drafting of the paper. All authors read and approved the final manuscript. There are no conflicts of interest.

\section{References}

1. Barasi ME (2003) Human Nutrition. A Health Perspective. London: Arnold.

2. Malina RM, Bouchard C \& Bar-Or O (2004) Growth, Maturation and Physical Activity, pp. 49-63, 2nd ed. Champaign, IL: Human Kinetics Europe Ltd.

3. Dwyer JT, Evans M, Stone EJ, et al. (2001) Adolescents eating patterns influence their nutrient intakes. J Am Diet Assoc 101, 798-802.

4. Story M, Neumark-Sztainer D \& French S (2002) Individual and environmental influences on adolescent eating behaviors. J Am Diet Assoc 102, S40-S51.

5. Timlin MT, Pereira MA, Story M, et al. (2008) Breakfast eating and weight change in a 5-year prospective analysis of adolescents: project EAT (Eating Among Teens). Pediatrics 121, e638-e645.

6. Siega-Riz AM, Carson T \& Popkin B (1998) Three squares or mostly snacks - what do teens really eat? A sociodemographic study of meal patterns. J Adolesc Health 22, 29-36.

7. Pearson N, Atkin AJ, Biddle SJ, et al. (2010) Parenting styles, family structure and adolescent dietary behaviour. Public Health Nutr 13, 1245-1253.

8. Pearson N, MacFarlane A, Crawford D, et al. (2009) Family circumstance and adolescent dietary behaviours. Appetite 52, 668-674. 
9. Keski-Rahkonen A, Kaprio J, Rissanen A, et al. (2003) Breakfast skipping and health-compromising behaviors in adolescents and adults. Eur J Clin Nutr 57, 842-853.

10. Linde JA, Wall MM, Haines J, et al. (2009) Predictors of initiation and persistence of unhealthy weight control behaviours in adolescents. Int J Behav Nutr Phys Act 6, 72.

11. Storey KE, Hanning RM, Lambraki IA, et al. (2009) Determinants of diet quality among Canadian adolescents. Can J Diet Pract Res 70, 58-65.

12. Woodruff SJ, Hanning RM, Lambraki I, et al. (2008) Healthy eating index-C is compromised among adolescents with body weight concerns, weight loss dieting, and meal skipping. Body Image 5, 404-408.

13. Pollitt E \& Mathews R (1998) Breakfast and cognition: an integrative summary. Am J Clin Nutr 67, 804S-813S.

14. Lien L (2007) Is breakfast consumption related to mental distress and academic performance in adolescents? Public Health Nutr 10, 422-428.

15. Nicklas TA, Baranowski T, Cullen KW, et al. (2001) Eating patterns, dietary quality and obesity. J Am Coll Nutr 20, 599-608.

16. Croezen S, Visscher TLS, ter Bogt NCW, et al. (2007) Skipping breakfast, alcohol consumption and physical inactivity as risk factors for overweight and obesity in adolescents: results of the E-MOVO project. Eur J Clin Nutr 63, 405-412.

17. Mikkila V, Rasanen L, Raitakari OT, et al. (2004) Longitudinal changes in diet from childhood into adulthood with respect to risk of cardiovascular diseases: the Cardiovascular Risk in Young Finns Study. Eur J Clin Nutr 58, 1038-1045.

18. Lien N, Lytle LA \& Klepp KI (2001) Stability in consumption of fruit, vegetables, and sugary foods in a cohort from age 14 to age 21. Prev Med 33, 217-226.

19. Patrick H \& Nicklas TA (2005) A review of family and social determinants of children's eating patterns and diet quality. J Am Coll Nutr 24, 83-92.

20. Tinsley BJ (2003) How Children Learn to be Healthy. Cambridge: Cambridge University Press.

21. Pearson N, Biddle SJ \& Gorely T (2009) Family correlates of fruit and vegetable consumption in children and adolescents: a systematic review. Public Health Nutr 12, 267-283.

22. Tibbs T, Haire-Joshu D, Schechtman KB, et al. (2001) The relationship between parental modeling, eating patterns, and dietary intake among African-American parents. $J \mathrm{Am}$ Diet Assoc 101, 535-541.

23. Pearson N, Biddle SJ \& Gorely T (2009) Family correlates of breakfast consumption among children and adolescents. A systematic review. Appetite 52, 1-7.

24. Soyer MT, Ergin I \& Gursoy ST (2008) Effects of social determinants on food choice and skipping meals among Turkish adolescents. Asia Pac J Clin Nutr 17, 208-215.

25. Woodruff S \& Hanning R (2009) Effect of meal environment on diet quality rating. Can J Diet Pract Res 70, 118-124.

26. Lau RR, Quadel MJ \& Hartman KA (1990) Development and change of young adults' perceived health beliefs and behaviors: influence from parents and peers. $J$ Health Soc Behav 31, 240-259.

27. O'Dea JA (2003) Why do kids eat healthful food? Perceived benefits of and barriers to healthful eating and physical activity among children and adolescents. J Am Diet Assoc 103, 497-501.
28. Contento IR, Williams SS, Michela JL, et al. (2006) Understanding the food choice process of adolescents in the context of family and friends. J Adolesc Health 38, 575-582.

29. Eisenberg ME, Neumark-Sztainer D, Story M, et al. (2005) The role of social norms and friends' influences on unhealthy weight-control behaviors among adolescent girls. Soc Sci Med 60, 1165-1173.

30. Farrow C, Haycraft E \& Meyer C (2011) Similarities between eating attitudes among friendship groups in childhood: the moderating role of child anxiety. J Pediatr Psychol 36, $1144-1152$.

31. Kremers SP, de Bruijn GJ, Visscher TL, et al. (2006) Environmental influences on energy balance-related behaviors: a dual-process view. Int J Behav Nutr Phys Act 3, 9.

32. Salvy S-J, Elmo A, Nitecki LA, et al. (2011) Influence of parents and friends on children's and adolescents' food intake and food selection. Am J Clin Nutr 93, 87-92.

33. Feunekes GI, de Graaf C, Meyboom S, et al. (1998) Food choice and fat intake of adolescents and adults: associations of intakes within social networks. Prev Med 27, 645-656.

34. Savige GS, Ball K, Worsley A, et al. (2007) Food intake patterns among Australian adolescents. Asia Pac J Clin Nutr 16, 738-747.

35. Wertheim EH, Mee V \& Paxton SJ (1999) Relationships among adolescent girls' eating behaviours and their parents' weight-related attitudes and behaviours. Sex Roles $\mathbf{4 1}$, 169-187.

36. Bandura A (1977) Social Learning Theory. Englewood Cliffs, New Jersey: Prentice Hall.

37. Campbell KJ, Crawford DA, Salmon J, et al. (2007) Associations between the home food environment and obesitypromoting eating behaviors in adolescence. Obesity 15, 719-730.

38. Hannon PA, Bowen DJ, Moinpour CM, et al. (2003) Correlations in perceived food use between the family food preparer and their spouses and children. Appetite 40, 77-83.

39. Littleton HL \& Ollendick TH (2003) Negative body image and disordered eating behaviour in children and adolescents: what places youth at risk and how can these problems be prevented? Clin Child Fam Psychol Rev 6, 51-66.

40. Wertheim EH, Paxton SJ, Schiutz HK, et al. (1997) Why do adolescent girls watch their weight? An interview study examining sociocultural pressures to be thin. J Psychosom Res 12, 345-355.

41. Paxton SJ, Schutz HK, Wertheim EH, et al. (1999) Friendship clique and peer influences on body image concerns, dietary restraint, extreme weight-loss behaviors, and binge eating in adolescent girls. J Abnorm Psychol 108, 255-266.

42. Ricciardelli LA, McCabe MP \& Banfield S (2000) Body image and body change methods in adolescent boys. Role of parents, friends and the media. J Psychosom Res 49 , 189-197.

43. Neumark-Sztainer D, Eisenberg ME, Fulkerson JA, et al. (2008) Family meals and disordered eating in adolescents: longitudinal findings from project EAT. Arch Pediatr Adolesc Med 162, 17-22.

44. Zabinski MF, Daly T, Norman GJ, et al. (2006) Psychosocial correlates of fruit, vegetable, and dietary fat intake among adolescent boys and girls. J Am Diet Assoc 106, 814-821. 